\title{
USO DE LAS VÍAS PECUARIAS Y ROTURACIONES: UNA CONFLICTIVIDAD HISTÓRICA ENTRE GANADEROS Y LABRADORES
}

\author{
Vicente Gozálvez Pérez \\ Departamento de Geografía Humana \\ Universidad de Alicante
}

\section{RESUMEN}

Desde el siglo XVIII, el declive económico y político de la ganadería ovina, por una parte, y el aumento demográfico y la necesidad de nuevas tierras de cultivo, por otro, activan los conflictos históricos entre ganaderos y labradores, que llevan a estos últimos a invadir y ocupar tanto tierras de pastos como veredas pecuarias limítrofes con sus tierras; además, en la densamente poblada y ocupada huerta del Bajo Segura, la pobreza de los jornaleros agrícolas también las lleva a invadir parte de la superficie de las «veredas de serranos», con barracas y viviendas. En los casos que se documentan, todos en la provincia de Alicante, se trata con frecuencia de apropiaciones de espacios ganaderos poco o nada utilizados, mientras que las intrusiones detectadas suelen ser consecuencia de causas variadas, como la pobreza de los «invasores», el desuso de las vías pecuarias, los daños que los cultivos pudieran sufrir con la presencia del ganado, etc. Ante las denuncias de los ganaderos contra los labradores que les impiden el uso de las antiguas vías pecuarias, la Asociación General de Ganaderos en los años en torno a 1900 emprende una activa campaña exigiendo a las autoridades locales y provinciales la delimitación y restitución de las vías pecuarias, de acuerdo con los derechos ganaderos consuetudinarios. En el último epígrafe se reconstruye con cierto detalle el proceso de deslinde y amojonamiento realizado en 1908-1910 para un pequeño tramo de antigua vía pecuaria de carácter general en el municipio de Alicante. En las conclusiones se revindica, además de la prístina función ganadera de 
las vías pecuarias, su uso social y lúdico, así como la defensa de su valor ecológico, todo ello según las exigencias de la Ley 3/1995 de Vías Pecuarias, que obliga a las Comunidades Autónomas al estudio, defensa y conservación de este patrimonio histórico.

Palabras clave: Vías pecuarias, ganaderos, labradores, roturaciones, provincia de Alicante, Asociación General de Ganaderos

\section{ABSTRACT}

Since the $18^{\text {th }}$ century, the economic and political decline of sheep farming, on the one hand, and the population increase and the need for new land for crops, on the other, triggered historical conflicts between stockbreeders and arable farmers, which led the latter to occupy both pastures and cattle tracks bordering on their lands. Furthermore, in the densely populated and heavily occupied fertile region of the Bajo Segura, poverty forced agricultural workers to invade part of the «veredas de serranos» and build houses on this land. In the cases documented herein, the farming areas appropriated were used infrequently or not at all, and the intrusions detected can be traced back to a range of causes including the poverty of the 'invaders,' the disuse of the cattle tracks, the damage to crops caused by cattle, etc. Following complaints filed by stockbreeders against arable farmers who denied the former use of the old cattle tracks, around the year 1900, the Asociación General de Ganaderos (General Association of Stockbreeders) commenced an active campaign to demand local and provincial authorities to limit and reinstate cattle tracks, in line with common farming rights. The last section of this paper includes a fairly detailed reconstruction of the demarcation and mark-out process undertaken in 1908-1910 on a small section of an old cattle track for general use in the municipality of Alicante. Our conclusions state that besides a primitive farming function, cattle tracks also fulfilled a social and recreational purpose, as well as considerable ecological value, in compliance with the demands envisaged in Law 3/1995 on Cattle Tracks, which obliges Autonomous Regions to study, defend and preserve this historical heritage.

Keywords: Cattle tracks, stockbreeders, farmers, tillage, province of Alicante, Asociación General de Ganaderos (General Association of Stockbreeders) 
La red viaria ganadera de España tiene trazado con orientación predominante norte-sur, y su intensidad aumenta sustancialmente al pormenorizar sobre la cartografía la jerarquía de las vías trazadas (cañadas, cordeles, veredas, coladas, azagadores, etc). Como es conocido, la formación de esta red viaria, realizada a favor de la ganadería ovina lanar, fue posible y necesaria, por una parte, a consecuencia de la alianza entre altos intereses económicos y políticos -al más alto nivel- tejidos en torno a la ganadería ovina lanar desde el siglo XIII, y, por otra, como respuesta a la necesidad de practicar estacionalmente la trashumancia de las ovejas en busca de pastos, pues estos estaban limitados por los condicionantes climáticos estacionales, pero que eran complementarios entre el norte-centro y el sur de la península (Cabo, 2004).

Las características del transporte tradicional de los ganados de ovejas en sus recorridos trashumantes, y también el pastoreo de los rebaños locales, provocaron desde siempre conflictos legales entre los ganaderos y los labradores cuyas tierras y cultivos pudieran verse afectados por vías pecuarias y la presencia de los ganados. Además, el paso de los ganados era estacional o con baja frecuencia, y anchas las vías ganaderas utilizadas. Con el paso del tiempo, llega el declive de la importancia económica de la ganadería ovina y, con ella, la limitación del poder económico y político de las instituciones ganaderas, mientras aumenta la densidad demográfica y del poblamiento, así como la importancia de la agricultura necesaria para alimentar a una población muy creciente durante el siglo XVIII.

Estos hechos propician que las tierras de pastos y las vías pecuarias, ambas poco frecuentadas, vayan siendo invadidas y apropiadas de forma ilegal tanto por los agricultores como por el hábitat rural, en contra de los intereses seculares de los ganaderos. En los casos locales de la provincia de Alicante que documentamos, se trata con frecuencia de apropiaciones de espacios poco o nada utilizados por la ganadería, mientras que las invasiones que padecen suelen ser consecuencia de causas variadas, como la pobreza de los «invasores», el desuso de las vías pecuarias, los daños que los cultivos pudieran sufrir con la presencia del ganado, etc.

Sin embargo, las vías pecuarias estaban protegidas por reglamentación legal y amojonamientos, y los ganaderos, por medio de sus asociaciones, a principios del siglo XX, ya en el inicio de su ocaso económico, exigen la vigencia de sus derechos consuetudinarios. Por su parte, la presencia de los labradores era, lógicamente, continua en los municipios y, con frecuencia, formaban parte de la sociedad local dominante. Así, ambos colectivos, ganaderos y labradores, se sienten seguros en sus pugnas y reivindicaciones frente a los abusos o perjuicios que provenían del otro colectivo. 


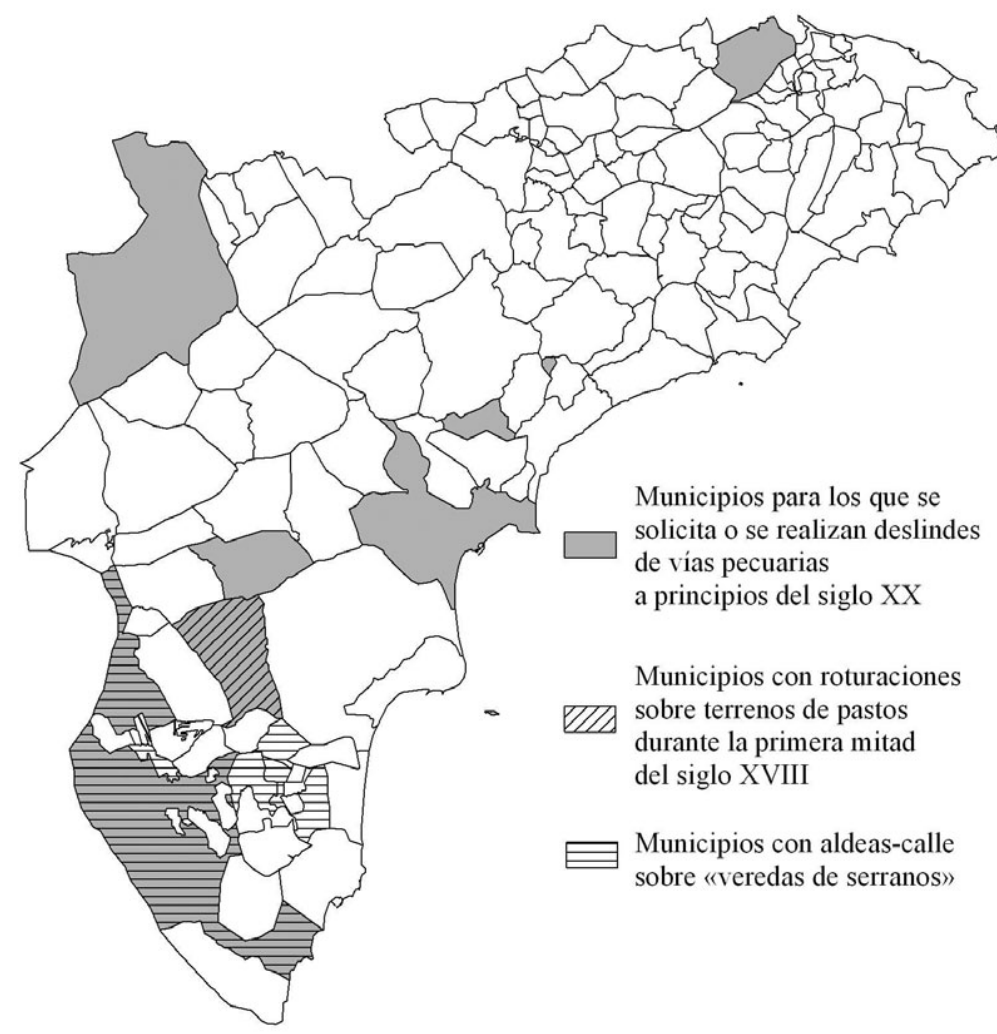

Fig. 1. Provincia de Alicante. Municipios para los que se documentan roturaciones sobre terrenos de pastos (s. XVIII), deslindes de vías pecuarias (s. XX) y aldeas-calle sobre «veredas de serranos» (s. XX).

Los casos que nos ocupan en este estudio, todos localizados en la provincia de Alicante (Fig. 1), hacen referencia a pequeñas pero generalizadas roturaciones agrícolas en el siglo XVIII (Crevillente); a la ocupación de parte de las veredas ganaderas como solares para viviendas de jornaleros agrícolas en el siglo XIX (huerta del Bajo Segura); y, sobre todo, a la necesidad de practicar, a principios del siglo XX, deslindes y amojonamientos de antiguos caminos ganaderos, pues su desuso había degenerado en estrechamiento de las vías principales o incluso en su desaparición para los menos frecuentados y/o de jerarquía viaria menor, lo que comprometía el paso de ganados o la misma existencia de los rebaños locales ante la oposición ganadera de los propietarios de las tierras agrícolas (Crevillente, Aspe, Pego, Villena, Orihuela, Alicante). Estos conflictos quedaban facilitados por una ganadería provincial muy 
escasa frente a una población densa respecto a la baja productividad agrícola y sin alternativas económicas suficientes, y, por tanto, sometida desde la segunda mitad del siglo XIX a fuertes presiones emigratorias, en ese momento sobre todo hacia la Argelia francesa. El último epígrafe de este estudio, reconstruye con cierto detalle el proceso de deslinde realizado en 1908-1910 para un pequeño tramo -unos $5,5 \mathrm{~km}$ - de antigua vía pecuaria de carácter general en el término municipal de Alicante, entre el Portichol y el abrevadero localizado en el Barranco de Aguas Amargas. En las conclusiones se reivindica, además de la prístina función ganadera de las vías pecuarias, su uso social y lúdico así como la defensa de su valor ecológico, todo ello según las exigencias de la Ley 3/1995 de Vías Pecuarias, que obliga a las Comunidades Autónomas al estudio, defensa y conservación de este patrimonio histórico.

\section{LA MESTA DENUNCIA LAS PEQUEÑAS ROTURACIONES SOBRE TERRENOS DE PASTOS EFECTUADAS DURANTE LA PRIMERA MITAD DEL SIGLO XVIII}

EL fuerte incremento demográfico registrado durante el siglo XVIII sin duda obligó a realizar numerosas roturaciones para ampliar las tierras cultivadas. En unos casos fueron operaciones planificadas y dirigidas por las autoridades -en el sur de la provincia de Alicante destacan las roturaciones efectuadas por el cardenal Belluga sobre terrenos pantanosos prelitorales, y las contiguas realizadas por el Marqués de Elche-, pero con frecuencia también se hicieron de forma ilegal sobre pequeñas superficies que en principio estaban destinadas a pastos. Los autores de estas últimas roturaciones generalmente fueron pequeños propietarios agrícolas que ampliaron sus parcelas a costa de superficies incultas o de pastos, al amparo del aislamiento de los terrenos roturados.

Para atajar estas conocidas - por generalizadas- roturaciones ilegales, un Real Decreto de 30-12-1748 dispuso que se informase al poder central sobre los terrenos de pastos que se habían roturado durante los últimos 20 años, lo que evidencia los intereses ganaderos. Para cuatro municipios de la comarca de Baza (Granada), G. Cano localizó las contestaciones a este R.D. en el Archivo Histórico Nacional (Cano, 1974: 205-206). En el caso del término municipal de Crevillente (Alicante), el informe sobre estas roturaciones fue localizado en el Archivo Municipal de Elche (Gozálvez, 1977: 68-71), con el expresivo título Crevillente. Año 1750. Dilixencias sobre los desmontes de pastos hechos en el término de esta Villa (Manuscrito, 53 folios).

Como indica este último documento, se trata de una «averiguación» de las roturaciones efectuadas sobre tierras de pastos, en contra de las leyes vigentes, 
ya que hay «noticia de los muchos [rompimientos] que en el término de esa villa se han executado contra leyes de estos Reynos...». Se ordena que dos «prácticos» o labradores naturales del municipio hagan el censo de dichas roturaciones, su antigüedad, ubicación, así como de los propietarios. Todas las roturaciones efectuadas en los veinte años anteriores a 1750 sin autorización real debían cesar como tales, bajo pena de 200 ducados, así como aquellas otras efectuadas con licencia temporal. Por separado, también se informaría sobre las roturaciones efectuadas antes de 1730, así como de las autorizaciones pertinentes, para ver si procedía su continuación como tierra cultivada o su reducción a pastos. Todas estas notificaciones las remitiría el municipio, por medio del corregidor correspondiente, al Marqués de la Ensenada.

Este censo de las «nuevas tierras» en Crevillente recoge 261 parcelas, pertenecientes a otros tantos propietarios, con una extensión total de 30l'6 hectáreas, es decir con una extensión media de l'l hectárea por parcela. La prohibición de seguir cultivando estas roturaciones ilegales, en el caso de Crevillente parece que quedó en suspenso a raíz de las diligencias hechas en Madrid a favor de la continuidad agrícola de estas parcelas, debido a la poca utilidad de estas tierras para el ganado, ya que «aquí no llega la Mesta» y la cabaña local era muy reducida, mientras las tierras agrícolas eran escasas y de poca productividad para la población del municipio que durante el siglo XVIII experimentó un fortísimo crecimiento.

En efecto, en 1739 Crevillente censaba unos 3.600 habitantes $^{1}$ y 5.927 en $1787^{2}$, lo que supone un incremento anual entre ambas fechas del 1'04 \%. Por su parte, los nacimientos registrados en los libros de bautismo de la parroquia local tuvieron una media anual de 158 durante la década 1730-39, y de 314 en 1780-89 (Gozálvez, 1983), es decir crecieron a razón de 1’38\% anual durante estos 50 años. Así, estos importantes incrementos demográficos justificaron la búsqueda de nuevas tierras de cultivo, en un municipio con serias dificultades económicas, derivadas tanto de la aridez y suelos agrícolas pobres, como de los fuertes gravámenes señoriales impuestos por el Marqués de Elche. A pesar de este entorno local de pobreza, los ganaderos consideraron -por

1. Archivo Municipal de Elche, Legajo 127-A: Noticia circunstanciada de los pueblos del Marquesado de Elche; Baronía de Aspe, Planes; y lugar de Patrax: su gobierno, vecindario, cultivos, pechos, diezmos, censos, etc, etc. (ms.) 31 folios, fechado en Elche el 12 de junio de 1739 (por el texto se deduce que el autor de esta "Noticia» es un subordinado del Marqués de Elche, probablemente su administrador). En concreto, para Crevillente este documento indica 800 vecinos.

2. Censo de Floridablanca. 
extensión- estas pequeñas roturaciones como una acción punible por atentar contra sus intereses legales.

Las tierras roturadas, siempre contiguas a respectivas propiedades de sus dueños, se localizaban en cañadas y apartadas de las zonas de descanso de los ganados, casi todas en terrenos más o menos montañosas como se deduce del nombre de los parajes en los que se censan estas roturaciones, efectuadas entre 1730 y 1750 . Estas «nuevas tierras» se habían cultivado de forma continua desde su roturación, dedicadas fundamentalmente a cebada.

\section{LAS ALDEAS-CALLE EN LA HUERTA DEL BAJO SEGURA (ALICANTE), OTRA FORMA DE «EXPOLIO»A LA GANADERÍA TRASHUMANTE}

La vega baja del río Segura tiene un hábitat rural muy denso, que se formó muy condicionado a favor de las posibilidades de la topografía, e incluso de la microtopografía, frente a las cíclicas inundaciones fluviales. No obstante, como es obvio también influyeron en la disposición del poblamiento otros factores locales como la red viaria, la del regadío, la propiedad de la tierra, los avances de la colonización agraria sobre los suelos en peores condiciones, además de la planificación oficial de nuevos núcleos e incluso para nuevo hábitat disperso. Todo ello en un marco de una agricultura hortícola y frutícola muy intensiva en cultivos y en productividad por superficie cultivada (Gozálvez, 1989).

La parte que ahora interesa es un poblamiento singular, el de las aldeascalle de una sola acera, que prolifera en toda la vega baja del Segura, entre San Fulgencio y la Vereda del Reino, antigua vía ganadera que en su día fue aprovechada para trazar el límite provincial entre Alicante y Murcia, heredero, a su vez, de los límites entre los reinos de Aragón y Castilla (Cabo, 2004; Gozálvez, 1975). Con trabajo de campo y suma de las filas de casas con longitud mínima de 100 metros, y máxima de hasta más de dos kilómetros, el conjunto total de las aldeas calle de una sola acera alcanzaba en 1988 a unos 24.000 metros, repartidos en 33 aldeas (Gozálvez, 1989).

La proliferación de este poblamiento en aldeas-calle tiene una doble base explicativa: por una parte, la existencia en esta huerta de una estructura social muy contrastada en el siglo XVIII, que ya denunció Cavanilles a finales de esa centuria (Cavanilles, 1797) después de un siglo con fortísimo crecimiento demográfico, como se deduce del incremento de bautismos (Gozálvez, 1972). Según el testimonio de Cavanilles, «... fáltales a infinitos la propiedad [de la tierra]; estos jornaleros vivían en pobres habitaciones e indecentes barracas... apenas tienen con qué subsistir aquellos hombres a cuyos sudores y fatigas se 
deben las cosechas» (Cavanilles, 1797, t.II: 281-282, 291-292). Por otra parte, esta difícil situación económica para la mayoría de la población huertana es la que forzó a los más desheredados a la construcción de barracas sobre «solares» públicos de veredas, pero ocupando sólo la mitad de la anchura de las antiguas «veredas de serranos», demasiado anchas para las necesidades de tránsito de la época. Debido a este origen del solar, las calles resultantes están formadas por sólo una acera o fila de casas; la otra mitad de la anchura de la vereda se respetó para la prístina función viaria. Con el paso del tiempo, según el testimonio de ancianos residentes (año 1988), las actuales casas sustituyeron durante 1930-1950 a las antiguas barracas. Para la edificación de las nuevas casas, según estos testimonios orales, en algunos casos se recababa autorización de los Ayuntamientos o de la Diputación Provincial, o simplemente se autoconstruía. A finales de los años 1980, en estas pecualiares aldeas ya menudeaban las viviendas en ruina parcial o total, mientras otras habían derivado a función de establo.

El carácter no privado y «limitado» del solar, ya que las veredas quedaban bordeadas por cauces de riego o por parcelas de cultivo, explican la posibilidad de edificación sólo en una de las mitades de la vereda. La morfología externa de las casas que forman las aldeas-calle es similar en toda la huerta del bajo Segura, pero tienen cierta diferencia según el tipo de veredas sobre las que se construyeron, es decir según fueran o no «veredas de serranos». Con el nombre genérico de veredas de serranos, los residentes locales designan aquéllas que fueron propiedad o utilizadas por los ganaderos trashumantes que procedían de las serranías de Teruel, y que utilizaban para cruzar transversalmente la vega con sus rebaños de ovejas; tales son las veredas de Liorna, Buenavida, Camino Viejo de Bigastro, la que une La Media Legua a La Campaneta, el Camino de Catral (en término de Almoradí), etc. Con el paulatino abandono de esta trashumancia, parte de estas veredas, sobre todo las más anchas, son las que utilizaron los jornaleros para la autoconstrucción de sus viviendas. El segundo tipo de veredas son las que recorren longitudinalmente la huerta, para unir los núcleos principales de población, como el Camino Viejo de Almoradí en dirección a Orihuela. Las aldeas-calle sobre el primer tipo de veredas son mucho más numerosas, pues eran de trazado original más recto, de calzada más ancha y menos transitadas; en consecuencia, las viviendas disponían aquí de más solar, y sus fachadas tienen alineaciones más regulares. 


\section{INTRUSIÓN Y DIFICULTADES DE PASO SOBRE LAS ANTIGUAS VÍAS PECUARIAS, SITUACIÓN HACIA 1900}

Una Memoria sobre la agricultura de la provincia [de Alicante] fechada en agosto de $1875^{3}$, testimonia con claridad que la ganadería tenía escasa importancia económica en la provincia: «como consecuencia lógica de la falta de pastos se cría muy poco ganado de todas clases. Algunas merinas, churras, de raza manchega y buen número de cabras es lo que sostienen los labradores con objeto de procurarse algún abono. Este, unido con el de los bueyes y mulas que viven para la labor, no suministran abono suficiente para las necesidades de la agricultura, teniendo que recurrir al guano del Perú, barreduras de las calles y algunas plantas marinas, con lo que pueden asegurarse en una pequeña porción de los terrenos de regadío buenas cosechas».

El texto anterior sobre la importancia de la ganadería provincial queda corroborado en 1878, cuando la Junta Provincial de Agricultura, Industria y Comercio de Salamanca solicita a su homónima de Alicante apoyo para pedir un deslinde general de las servidumbres pecuarias, al objeto de «evitar los conflictos que con frecuencia tienen lugar entre ganaderos y labradores de predios colindantes con las servidumbres pecuarias...y teniendo en cuenta que ha desaparecido por las intrusiones gran parte del terreno perteneciente a dichas servidumbres, ha acordado acudir al Consejo Superior del ramo en súplica de su poderoso concurso para conseguir se decrete el deslinde general de las servidumbres pecuarias, proponiendo a la vez que en lo sucesivo queden éstas bajo la inspección de las Juntas Provinciales de Agricultura». La respuesta de la Sección de Ganadería de Alicante (28-06-1878) es de apoyo «por convenir a los intereses pecuarios del país en general», pero que «en la provincia [Alicante] no tiene gran importancia el asunto de que se trata por la escasez de ganado, pastando éstos en los terrenos de los mismos dueños» ${ }^{4}$.

Por otra parte, este oficio de la Junta Provincial de Agricultura de Salamanca de 1878, testimonia expresamente el conflicto generalizado en España entre labradores y ganaderos en aquellos años, y el deseo de los salmantinos de liderar un movimiento nacional para restaurar usos ganaderos aminorados

3. Archivo de la Diputación Provincial de Alicante (en adelante ADPA), Legajo 16642/2. Esta Memoria, redactada en escasos meses, fue encargada por la Junta Provincial de Agricultura, Industria y Comercio de Alicante, Sección de Agricultura, a su Secretario D. Augusto Echevarría, Ingeniero Agrónomo. El manuscrito consultado consta de cinco capítulos: 1. Situación, clima, terreno e importancia comercial de la provincia de Alicante. 2. Estado actual de la agricultura en la provincia de Alicante. 3. Cultivos principales.

4. Riegos de la provincia. 5. Medios de mejorar la agricultura.

4. ADPA, Legajo 16642/5. Documento fechado el 31-05-1878. 
o, simplemente, desaparecidos a favor de la expansión agrícola, aunque ésta, aún así, era insuficiente para atender las necesidades laborales de la época ${ }^{5}$.

En 1908, un oficio de la Dirección General de Agricultura, Industria y Comercio dirigido al Jefe de Fomento de Alicante, señala que el Ministerio el 6 de mayo de 1908 suspendió los trabajos para la formación estadística pecuaria, en espera de los datos [provinciales] que debía publicar la Asociación General de Ganaderos del Reino, que una vez depurados por el Consejo Provincial de Agricultura y Ganadería se les daría valor oficial ${ }^{6}$. Pero la minuta de respuesta de dicho Consejo, señala que la estadística pecuaria sobre Alicante publicada por la Asociación de Ganaderos ofrece «cifras demasiado elevadas dada la corta extensión superficial, falta de aguas y pocos pastos... [es] inadmisible el número de cabezas que se fijan de ganado vacuno en la cifra de 22.570 cuando las estadísticas de la provincia sólo dan la de 2.500 cabezas para dicho ganado»; igualmente estiman muy exageradas las cabezas de ganado lanar -100.300 según la Asociación, 50.500 según el Consejo Provincial-, ganado de cerda -49.000 contra 22.000- y cabrío -40.600 contra 25.000-.

Pese a la escasa importancia que las diversas fuentes indicadas constatan para la ganadería en la provincia de Alicante, los conflictos entre ganaderos y labradores parece que sí son generalizados en la provincia a principios del

5. En el caso de Alicante, la Memoria sobre la agricultura de la provincia redactada en 1878 por el ingeniero agrónomo A. Echeverría, citada en la nota 3, se afirma que «...la emigración a África que iba tomando en estos últimos tiempos un incremento aterrador», sólo es contenida por las fábricas de Alcoy y Crevillente.

Este conocido proceso emigratorio (para el caso de Alicante, vid., entre otros, Bonmatí, 1989; Gozálvez, 1977), despertó fuerte inquietud en las autoridades, pues en 1881 el Ministerio de Fomento, por medio de los Gobiernos provinciales, ordenaba a las corporaciones contestar un Interrogatorio para estudiar las causas de la emigración. En la contestación -la orden del Gobierno de la provincia se publicó en el Boletín Oficial de la Provincia el 21-08-1881- de la Junta Provincial de Agricultura, Industria y Comercio de Alicante al citado Interrogatorio, se indica que «Desde la conquista de Argelia por los franceses empezaron los habitantes de esta Provincia a emigrar periódicamente a las costas africanas, regresando unos anualmente a sus casas, y quedándose otros allí establecidos. ... esta Junta... cree seguro que existen hoy establecidos en la Argelia más de cincuenta mil hijos de esta Provincia». Como causa de la emigración, la Junta indica «La falta de lluvias que hace tiempo viene notándose en esta comarca, hasta el punto de transcurrir a veces muchos años sin que los labradores lleguen a recolectar sus cosechas». Sobre los movimientos migratorios informa: «En la época de siega han acostumbrado siempre los braceros de esta Provincia dirigirse a la Mancha y Castilla en busca de trabajo, pero esta emigración decrece de año en año, porque también para la siega prefieren dirigirse, y la mayoría se dirige a la Argelia, regresando luego a sus hogares... El único medio de contener la emigración en esta Provincia sería la construcción de canales de riego, que fertilizando los campos proporcionasen seguro y constante trabajo a los braceros». ADPA, Legajo 16651/4.

6. ADPA, Legajo 16571/8. Documento fechado el 5-10-1908. 
siglo XX, a juzgar, sobre todo, por los numerosos escritos de protesta que el activo Presidente de la Asociación General de Ganaderos del Reino, Duque de Veragua, envía desde Madrid, hacia 1908, con destino a las autoridades provinciales:

a) Para el caso de Crevillente, el escrito dirigido al Jefe de Fomento el 1-071908 señala que «los ganaderos de Crevillente se ven perseguidos constantemente por la Comunidad de Labradores que no les permiten transitar con sus ganados por los caminos pastoriles ni por los vecinales...» pese al carácter público de unos y otros, «...y en tal concepto el Juzgado de Elche ha fallado juicio absolviendo a los ganaderos. El Gobernador Civil de esa provincia ordenó el 10-08-1907 a la Alcaldía de Crevillente abriese enseguida pública información para determinar los caminos pastoriles, abrevaderos y descansaderos con la intervención de esta Asociación, sin que hasta la fecha se tenga noticia de haberse realizado» ${ }^{7}$.

b) Respecto al municipio de Aspe, el oficio de la Asociación del 4-04-1908 al Jefe de Fomento de Alicante, informa que «... D. Fernando Pérez ha sido denunciado y maltratado por el Jurado de la Comunidad de Labradores con motivo de cruzar con su ganado por una vía pastoril, la cual se halla intrusada por el vecino D. Juan Botella Galván,... y los ganados continúan sufriendo los perjuicios que les ocasiona las denuncias del Sindicato de Labradores... que por la Alcaldía se cumpla lo que está prevenido a los efectos del deslinde de las vías pecuaria de aquel término» ${ }^{8}$.

c) Igualmente en Pego, la Asociación denuncia ante el Gobernador Civil (23-08-1904) que «... la ganadería de dicha localidad viene sufriendo grandes perjuicios por hallarse interceptadas... se pidieron antecedentes al Visitador municipal para solicitar su deslinde con arreglo a Reglamento... la Alcaldía se ha negado a practicar el deslinde...». La petición de deslinde se reitera el 15-03-1909 ante el Jefe de Fomento de la provincia9.

d) En Villena, la Asociación sí constata en 1909 que existe expediente de deslinde de todas las vías pastoriles del término ${ }^{10}$.

e) En Orihuela, la Asociación también testimonia que se han ejecutado deslindes de diversas vías pecuarias, aunque aminorando el ancho de la vía ganadera principal que pasa por el término, a favor de los labradores con

7. ADPA, Legajo 16571/8.

8. ADPA, Legajo 16571/8.

9. ADPA, Legajo 16571/8. Por decretos de 25 de octubre y 20 de diciembre de 1907, se traspasa a los Jefes de Fomento provinciales las competencias sobre este tema que antes tenían los Gobernadores Civiles.

10. ADPA, Legajo 16571/8. 
parcelas limítrofes. El informe del Visitador de ganadería y cañadas de Orihuela que se transcribe a continuación, nos interpreta las vicisitudes que experimentan las vías pastoriles de gran amplitud, en su proceso de pérdida de funciones ganaderas y apropiación por parte de los labradores con tierras limítrofes a ellas. En efecto, el 10-03-1908 la Asociación de Ganaderos indica al Jefe de Fomento de Alicante que, según el informe enviado a la Asociación, «el Visitador de ganadería y cañadas de Orihuela manifiesta con fecha 23 del pasado lo que sigue: «He de manifestarle que el 21 del corriente se terminó el deslinde, por la comisión de la que formo parte [el visitador], de la Cañada que desde Cuenca y Valencia, viene a pasar por Yecla donde está amojonada con sus 90 varas [75'23m] y sigue hasta después de Pinoso, si [bien] aquí no [está] amojonada con su anchura correspondiente. Ya desde este sitio está casi toda roturada, y como quiera que aquí desconocen las clases de vías pecuarias, y todas ellas las denominan veredas, hasta en las escrituras que tienen los colindantes, estos quieren que con arreglo a esto se haga el deslinde que como vereda sabe es de 25 varas [20'89 metros]. En vista de este erróneo derecho que creen les asiste porque como antes le digo todos los títulos hacen referencia a veredas y no cañadas, el ingeniero de la Comisión quiere, según me hizo presente, dar el informe y que se apruebe como vereda, siendo así que es cañada, de lo cual protesté en el acto... $\gg^{11}$.

Si este deslinde y circunstancias que describe el Visitador de Orihuela está referido a la Cañada que desde Orihuela se dirige a Elche, para terminar, seguramente como ramificación, en el Abrevadero del Barranco de Aguas Amargas, tendríamos el fundamento histórico para declarar Cañada el tramo de la vía pastoril desde el Portichol al abrevadero de Aguas Amargas (término de Alicante), tal como fue publicado en el BOE de 25-02-1955 (p.863), a propuesta del informe redactado por el perito agrícola D. Francisco Vázquez Gabaldón, de lo que se tratará más adelante.

A continuación, el 25-04-1908 el Consejo Provincial de Agricultura y Ganadería de Alicante, envía al Jefe Provincial de Fomento el siguiente oficio: «En la sesión celebrada por este consejo el 15 de abril fue aprobado por unanimidad el informe de la sección de Ganadería [que dice] «Examinado el expediente de la práctica del deslinde de la vía pecuaria que pasa por el caserío de Arneva [término municipal de Orihuela]..., con la protesta de todos los propietarios de fincas colindantes, si bien se han cumplido las formalidades... la variación del nombre de dicha vía pecuaria, que en otro deslinde que no llegó a ser aprobado se denomina Cañada y como tal fue anunciado

11. ADPA, Legajo 16571/8. 
su deslinde, y la Comisión ahora estima fundamentado sea Vereda y que se observe el ancho medio que indica el Reglamento [de 13 de agosto de 1892] de 20'89 metros, en vez de los 75'23 que corresponde a la Cañada...». Según oficio de la Asociación de Ganaderos de 31-07-1908, esta institución abonó 463 '64 pesetas «para los gastos de deslinde de las vías pecuarias del término de Orihuela», y el 13-10-1908 reclamaba al Jefe de Fomento de Alicante que remitiese $« \ldots$ a esta corporación el plano y copia de las actas del deslinde practicado en las vías pecuarias del término de Orihuela» ${ }^{12}$.

\section{DESLINDE Y AMOJONAMIENTO DE UNA VÍA PECUARIA HISTÓRICA EN LA LADERA NORTE DE LA SIERRA DE COLMENARES (ALICANTE), REALIZADO EN 1910}

La documentación conservada en archivos nos permite seguir la evolución pormenorizada del «deslinde de la vía pecuaria de carácter general en su trayecto desde el Portichol al abrevadero de Aguas Amargas», realizado en 1910, así como de sus antecedentes inmediatos iniciados en 1908. Como señala la documentación conservada, los motivos para plantear y ejecutar este deslinde son muy similares al resto de casos enumerados en el epígrafe anterior, es decir las reivindicaciones de los ganaderos y de su Asociación General, con sede en Madrid, basadas en la legislación existente, ante la negativa de los labradores a que los ganaderos transiten por las antiguas vías pecuarias, precisamente por haber caído en desuso estas vías ante su escasa frecuentación.

La evolución de este caso de la Sierra de Colmenares durante el siglo XX sin duda alcanza interés especial, pues de la casi total desaparición del antiguo trazado de esta vía pecuaria en 1910, primero se rehabilitó su deslinde en ese año, seguramente motivado por la importancia histórica y «estratégica» de esta vía pecuaria, ya que desde su inicio en la confluencia de dos antiguas vías ganaderas en el Portichol, el tramo deslindado y amojonado daba acceso a un abrevadero necesario para el ganado, situado a 5 '5 km de la confluencia viaria indicada. El deslinde de 1910 se hace como vereda, con anchura de «unos 22 metros», la misma que tenía el amojonamiento histórico anterior. En segundo lugar, resulta llamativo que este tramo de vía pecuaria entre el Portichol y el abrevadero, en 1955 se eleva a rango de «Cañada Real» según una orden del Ministerio de Agricultura de 31 de enero de 1955, publicada en el Boletín Oficial del Estado de 12-02-1955, otorgándole la anchura oficial de cañada, es decir $75 ’ 22$ metros, lo que tendrá notable importancia económica en la actualidad, ante la urbanización de esta zona periférica de la ciudad de Alicante (Fig. 2).

12. ADPA, Legajo 16571/8.

Investigaciones geográficas, $n^{\circ} 54$ (2011) 


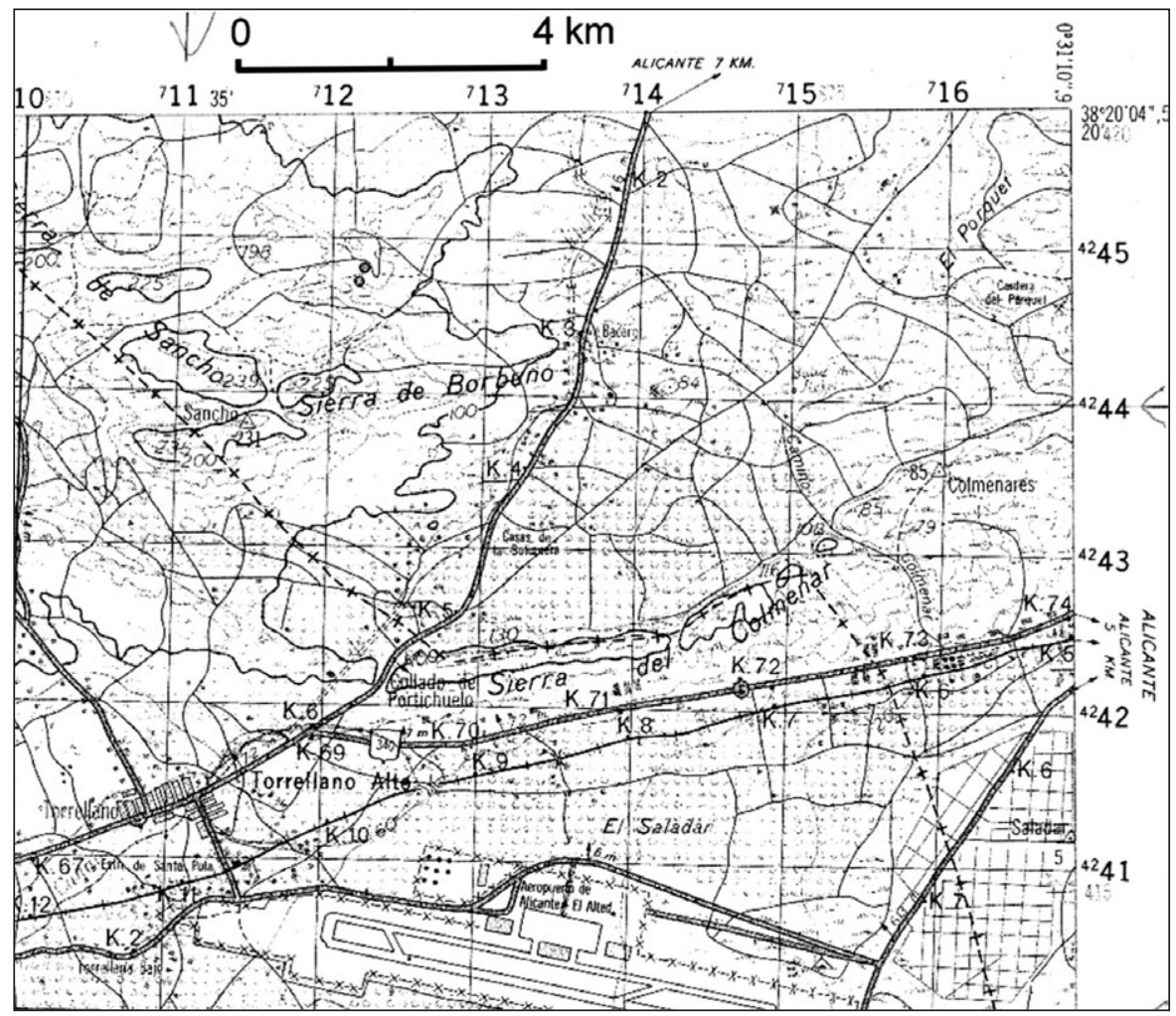

Fig. 2. Mapa Topográfico del Servicio Geográfico del Ejército, Hoja Elche 893, Escala original 1:50.000. Área de la Sierra de Colmenares entre los términos de Alicante (norte) y de Elche (sur), donde se localiza la vía pecuaria histórica entre el Portichol (en el mapa «Collado del Portichuelo») y el Barranco de Aguas Amargas (fuera del mapa, al este), cuyo deslinde y amojonamiento se practicó en 1910. Entre el Portichol y el Camino de Colmenares, la vereda fue delimitada en la vertiente norte de la Sierra, junto a la línea de cumbres, y en la vertiente sur entre el Camino de Colmenares y el Barranco de Aguas Amargas. (Año de edición del mapa 1990).

\subsection{La Cámara Oficial de Alicante plantea en 1908 la necesidad de realizar el deslinde de la vía pecuaria}

Los ganaderos que utilizaban la ahora llamada «Cañada Real del Portichol», parece que a principios del siglo XX también soportaban la vigilancia restrictiva de los agricultores locales. En efecto, el Presidente de la Cámara Oficial Agrícola de Alicante, con fecha 5-01-1908, remite el siguiente oficio al Jefe de Fomento de la provincia: «Teniendo que resolver la Junta Directiva de esta Cámara Agrícola una consulta elevada por dos de sus socios sobre si tienen 
derecho a transitar o no los ganados por las veredas del monte llamado Sierra de Colmenares, situado en la partida de Bacarot, término de esta ciudad, ruego a V.S. se sirva solicitar de la superioridad las disposiciones legales que regulan el uso de las vías pecuarias, así como también los antecedentes que consten en aquel centro referentes a dicha Sierra de Colmenares y facilitarlos a esta Cámara» ${ }^{13}$.

La Asociación General de Ganaderos del Reino, en escrito fechado en Madrid el 10-03-1908 dirigido al Jefe de Fomento de la provincia de Alicante, especifica que, en respuesta al escrito de este último, «adjunto se acompaña un tomo en el que están recopiladas las disposiciones referentes a vías pecuarias, significándole que teniendo las mismas carácter de dominio público, su uso no puede impedirse ni limitarse a la ganadería, conviniendo que cuando atraviesen montes públicos, se amojonen en forma reglamentaria por una Comisión compuesta de un representante del distrito forestal, otro de esta Asociación y de individuos del Ayuntamiento en cuyo término se halle enclavado el monte, levantándose acta por triplicado, para que cada una de las representaciones obtenga un ejemplar para que en lo sucesivo puedan con ellas solventar las dudas y contiendas que se susciten ${ }^{14}$.

El Presidente de la Cámara Agrícola de Alicante, el 31-08-1908 vuelve a dirigir nueva consulta al Jefe de Fomento de la provincia «En virtud de la consulta elevada por socios de esta Cámara sobre el derecho de tránsito de los ganados por la Sierra de Colmenares, y en virtud de los antecedentes obtenidos del Registro de la Propiedad de este Partido. Resultando: que el monte denominado Colmenares, situado a la parte oeste de esta ciudad, distante 5 kilómetros de la misma, está atravesado por un azagador desde E. a O. por la falda norte y fue vendido por el Estado a Don Jorge María Barrera Mingot en subasta rematada en 2 jl. 1869 según escritura de 8 feb. 1870... y hoy perteneciente a diferentes dueños por transmisiones de dominio posteriores. Que la Junta Directiva de esta Cámara... es de opinión que debe deslindarse el azagador que atraviesa el Monte Colmenares como vía pecuaria, para lo cual se ha de iniciar la petición por el Consejo Provincial de Agricultura y Ganadería a quien compete recabar de la superioridad la referida operación, $\ldots »^{15}$.

Por su parte, la Asociación General de Ganaderos del Reino el 19-10-1908 envía escrito al Jefe de Fomento de la provincia de Alicante en contestación al oficio de este último fechado el 28-09-1908: «En el Archivo de esta Corporación no aparecen datos del azagador que atraviesa de E. a O. y por la falda

13. ADPA, Legajo $16571 / 8$

14. ADPA, Legajo 16571/8.

15. ADPA, Legajo 16571/8.

Investigaciones geográficas, $n^{\circ} 54$ (2011) 
N. el monte denominado Colmenares a que se refiere la comunicación que ha dirigido a V.S. la Cámara Agrícola de esa ciudad; pero siendo monte del Estado, el deslinde y amojonamiento de las vías pecuarias que por el mismo atraviesan debe practicarse por los ingenieros del Distrito Forestal según previene la orden circular de la Dirección General de Agricultura de 8 de mayo de 1908, con la intervención de un representante de esta Asociación General de Ganaderos, de cuya operación se levantará el acta y plano correspondiente, de los que se expedirán copias para esta Corporación y la Municipal de esa ciudad $»^{16}$.

Queda patente, pues, la existencia y uso ganadero en 1908 de una vía pecuaria histórica en la ladera norte de la Sierra de Colmenares. También queda manifiesto cierto desconocimiento en los organismos oficiales locales de los labradores sobre la legislación que rige el uso por parte de los ganaderos de tales vías pecuarias, de lo que se deriva imprecisión en la nomenclatura de las vías pecuarias, pues la de la Sierra de Colmenares es calificada indistintamente de azagador y de vereda. En el Archivo de la Asociación General de Ganaderos parece que, según su oficio de 19-10-1908, no existía información sobre la vía pecuaria que recorre la ladera norte de la Sierra de Colmenares.

Por otra parte, en los documentos de 1908 consultados y ya citados en el apartado 3 de este estudio, especialmente el redactado por el visitador de ganadería y cañadas de Orihuela, la nomenclatura de las vías pecuarias, que comportan distintas anchuras en tales vías, son objeto de discusión, que se apoya bien en intereses de los propietarios de las tierras vecinas a las veredas, pues éstos amplían sus tierras a costa de las vías pecuarias, bien en el uso popular de una terminología no específica, pero que sirve a los intereses de los propietarios agrícolas.

\section{2. "Deslinde de la vía pecuaria de carácter general en su trayecto desde el Portichol al abrevadero de Aguas Amargas»}

El Boletín Oficial de la provincia de Alicante no 39, de 19-02-1910, publicó la orden del Jefe de Fomento sobre deslinde de la vía pecuaria que se indica en el encabezamiento de este epígrafe, lo que se efectuaría de acuerdo con el Reglamento de la Asociación General de Ganaderos de 13 de agosto de 1892, y de conformidad con lo dispuesto por la Presidencia de dicha Asociación. El abrevadero, extremo oriental de la vía pecuaria a deslindar, motivo del deslinde, se encontraba en la finca propiedad de $\mathrm{D}^{\mathrm{a}}$ Asunción Casanova, en la partida de Bacarot, término de Alicante, mientras el Portichol se situaba en

16. ADPA, Legajo 16571/8. 
el extremo occidental de dicha vía, entre los términos de Elche y Alicante, y arrancaba en la confluencia de dos vías pecuarias procedentes del término de Elche. Los trabajos de deslinde se iniciarían el 28-03-1910.

Asimismo, el Jefe Provincial de Fomento el 19-02-1910 firmaba el siguiente oficio dirigido al alcalde de la ciudad de Alicante: «Con fecha de ayer he acordado la práctica de deslinde de la vía pecuaria de este término municipal, según se indica en el número 39 del Boletín Oficial de hoy; lo que con arreglo al artículo 88 del Reglamento de la Asociación General de Ganaderos de 13 de agosto de 1892 trasladará oportunamente a todos los dueños de terrenos colindantes y por el artículo 89 dispondrá el nombramiento del personal.... así como cumplimentar los edictos que previene el art. $91 \ldots .{ }^{17}$.Por su parte, D. Luis Pérez Bueno, Abogado, Alcalde Constitucional de Alicante, el 10-031910 firmaba un bando por el que hacía saber «Que el día 28 del corriente, y ante la Comisión designada al efecto, tendrá efecto el deslinde de la vía pecuaria de carácter general en su trayecto desde el Portichol al abrevadero de Aguas Amargas, existente en la partida rural del Bacarot de este término municipal $\gg^{18}$. El mismo día 10-03-1910 el Alcalde de Alicante dirigía al Alcalde de la Partida Rural de Bacarot, el siguiente oficio: «Debiendo tener efecto el día 28 del corriente el deslinde de la vía pecuaria de carácter general en su trayecto desde el Portichol al abrevadero de Aguas Amargas, existente en esa partida, finca de Doña Asunción Casanova, sírvase V. dar conocimiento de ello a la interesada en un plazo brevísimo, así como a los demás propietarios interesados, para que por sí o por medio de su Apoderado, concurran dicho día al expresado deslinde. Igualmente propondrá a esta Alcaldía con toda urgencia el nombre de tres ancianos conocedores de la vía de que se trata para que asesoren a la Comisión que se nombre al efecto» ${ }^{19}$.

Por su parte, el 17-03-1910 el Alcalde [pedáneo] de la Partida de Bacarot, término municipal de Alicante, firmaba el siguiente oficio: «He Recivido del Ayuntamiento de Alicante una comunicación en que me dice que todos los que tengan fincas en la bereda desde el Portichol a aguas amargas se presentara el día 28 del mismo para que presencien su deslinde acompañaran tres ancianos de hombres buenos de dicha partida para que firmen los deslindes y queden enterados; que saldrá una comisión de Alicante a investigar los terrenos» (siguen nueve firmas) ${ }^{20}$.

17. Archivo Municipal de Alicante (en adelante AMA), Central, Legajo 84, exp.8.

18. AMA, Central, Legajo 84, exp.8.

19. AMA, Central, Legajo 84, exp.8.

20. AMA, Central, Legajo 84, exp. 8. 
El mismo 17-03-1910 el Alcalde de Alicante, dirigió al Jefe Provincial de Fomento el siguiente oficio: «Contestanto la atenta comunicación de V.S. fecha 19 de febrero último, y después de practicadas las diligencias en la misma referidas, debo manifestarle que en el tablón de edictos de este Ayuntamiento y en los periódicos de la localidad, se ha puesto en conocimiento del vecindario que el día 28 del corriente tendrá efecto el deslinde de la vía pecuaria de carácter general, situada en la partida rural de Bacarot, desde el Portichol al abrevadero de Aguas Amargas, habiéndose ordenado al alcalde de dicha partida que notifique a todos los propietarios colindantes. Los ancianos que han de formar parte de la Comisión son los siguientes: Rafael Sempere Segarra, Juan Esteve Palomares y Manuel García Escolano ${ }^{21}$.

En oficio del Gobierno Civil de la provincia de Alicante, Servicio Agronómico, fechado el 7-12-1912, dirigido al Alcalde de Alicante ${ }^{22}$, se indica «En el expediente de deslinde de la vía pecuaria en su trayecto desde el Portichol al abrevadero de Aguas-amargas, partida de Bacarot en el término de Alicante, he resuelto lo siguiente:

«Considerando que en el informe del Delegado que presidió la Comisión del deslinde de la vía pecuaria que viene por la sierra Larga y atraviesa el monte llamado Colmenares para que puedan transitar los ganados a los abrevaderos Torrosella y Agua-amarga, se extractan los trabajos efectuados según se indica extensamente en las 8 actas que se acompañan y que después de rectificar trabajos, reconocer hitos antiguos y fijación de otros nuevos con anuencia de los colindantes y conformidad de la Comisión; quedando perfectamente deslindada y amojonada la Vía pecuaria, lo que permitió el levantamiento del plano que también se adjunta con una longitud total de 5.433 metros y un ancho promedio del de las veredas, anotándose además que se trata de terrenos muy deficientes de poner en cultivo por la aridez y fuertes pendientes, siendo el esparto la única planta estimable que se halla por aquellos terrenos. Aprobar las operaciones llevadas a efecto por la Comisión que ha practicado el deslinde, de conformidad con las actas y plano obtenido. Lo que comunico a V.E. para su conocimiento y notificación en forma a la Cámara Oficial Agrícola de Alicante y a los herederos de Don Jaime Bonmatí, sirviéndose acusarme recibo de ello».

En efecto, en la Sección de Vías Pecuarias de la Delegación Territorial de Alicante de la Conselleria de Territori i Habitatge se conserva una «Copia autorizada de las actas de deslinde de la vía pecuaria del Portichol al abrevadero

21. AMA, Central, Legajo 84, exp. 8.

22. AMA, Central, Legajo 84, exp. 8. 
de aguas amargas, en término de Alicante» ${ }^{23}$. Según esta copia, la Comisión de deslinde inició sus trabajos el 28 de marzo de 1910, y los finalizó el 22 de abril de $1910^{24}$.

En el acta del día 28 se indica «... en cumplimiento de lo dispuesto en el anuncio publicado en el número 39 y siguientes del Boletín oficial correspondiente al 19 de febrero último, se procedió al deslinde de la vía pecuaria, que según manifestación de los ancianos, peritos prácticos, viene de la Sierra Larga y atraviesa el monte Colmenares, por su parte N. y dirección de O. a E. hasta llegar al barranco de Aguas Amargas, donde existe el abrevadero del mismo nombre, límite de las operaciones de deslinde que ha de practicarse en los días sucesivos. Como trabajo preliminar se procedió a levantar el plano de la parte de la vía pecuaria radiante en el término de Elche, que al atravesar el Portichol, cruza la carretera de Alicante a Crevillente, dando un rodeo con motivo del desmonte que se hizo para la construcción de dicho ferrocarril25, pues según indicaron los prácticos, anteriormente a estas obras los ganados venían por la ladera $\mathrm{N}$. de la sierra y por la misma vertiente marchaban hasta Aguas Amargas; pero en la actualidad al llegar a las proximidades de la Caseta de la Guardia Civil, que se detallará en el plano, pasan los ganados entre ésta y la carretera bajando paralelamente a la misma y al llegar a la curva donde termina el desmonte la atraviesan como igualmente en un paso a nivel la vía férrea mencionada para retroceder de nuevo; y por el lado opuesto, subir por la ladera de la vertiente Sur pasando entre los mojones A y B que marcan la línea divisoria de la propiedad de los herederos de D. José Ruiz y D. Remigio Sebastián y continuar por la cumbre de la Sierra hasta donde dijeron los prácticos existía el mojón de divisoria de término entre Alicante y Elche, que en la actualidad no queda indicios ni la menor señal que lo justifique y desde este punto baja por una depresión del terreno y llega de nuevo a la vertiente norte de la Sierra o monte Colmenares y entrada en el término de Alicante, de cuyo recorrido se tomaron los datos necesarios, suspendiéndose por este día las operaciones de deslinde...».

23. Esta copia fue expedida en Madrid el 10 de julio de 1942 por D. Carlos Grau Campuzano, Licenciado en Derecho y Archivero del Sindicato Nacional de Ganadería, con el visto bueno del Secretario Nacional del Sindicato Nacional de Ganadería y autorizada con el sello del mismo. La copia tiene siete páginas mecanografiadas.

24. La Comisión estuvo compuesta por D. Daniel García Llorca, Presidente, tres ancianos peritos D. Rafael Sempere, D. Juan Esteve y D. Manuel García; los Concejales D. Juan Langucha y D. Vicente Ripoll, y el Agregado Pedáneo de Bacarot D. José Sempere.

25. La carretera y el ferrocarril que pasan por el Portichol y a las que hace referencia el acta de deslinde de 1910 son, respectivamente, la carretera de Bacarot A-422 ó del Alto de las Atalayas (Alicante) a Murcia (1865-1872) y el tranvía Alicante-Elche-Crevillente, proyectado en 1894 y en explotación entre 1905 y 1912 (Vid. Gozálvez Pérez, Vicente, Crevillente. Estudio urbano y demográfico, Valencia, Departamento de Geografía, Facultad de Fiolosofía y Letras, 1971, 133p. +8 láms. f.t. Cf. p. 30-31. Gozálvez Pérez, V., La ciudad de Elche. Estudio Geográfico, Departamento de Geografía, Universidad de Valencia, 1976, 290 p. +VII láms- f.t. Cf. p. 109-110. 
«Acta del día 29. Reunidos nuevamente los señores de la Comisión en el punto y sitio que quedaron suspendidos los trabajos de deslinde en el día anterior con asistencia de varios colindantes, dueños de las tierras que confinan con el monte Colmenares, propiedad de los herederos de D. Jaime Bonmatí, manifestaron los prácticos que la vía pecuaria marcha por la falda de dicho monte, sin poder fijar con precisión su eje o anchura. En su consecuencia se procedió a deslindar las tierras con el monte mencionado,....., por lo avanzado de la hora se suspendió la operación sin que los propietarios asistentes a este acto formulasen la menor protesta».

Acta del día 30. Continúan las operaciones de deslinde. «.... Al llegar al final del deslinde de esta finca, los peritos prácticos, colmos e individuos dueños o propietarios de las tierras limítrofes que acompañan a la Comisión, manifiestan que en la ladera del monte existen hitos o mojones de la Vereda o arador [azagador, i], como aquellos llaman a la vía pecuaria que se está deslindando, cuyos hitos se encuentran a bastante distancia de las tierras y separados del crestón de rocas del monte Colmenares, divisoria de sus vertientes N. y S. a unos 30 metros en línea normal a la pendiente del terreno que oscila alrededor de 30 grados, donde se pudo apreciar la dirección y anchura del camino pastoril, objeto de este deslinde, que es la faja de terreno comprendido entre las rocas y los hitos encontrados o sea en proyección horizontal un ancho de unos 22 metros poco más o menos. Prosiguiendo la operación de deslinde y llevando como norma la toma de datos de toda la ladera y vertiente $\mathrm{N}$. del monte, entre el crestón de las peñas y las tierras labrantinas [labrantías] que lindan en su base, llegamos al barranco de Morriquet, donde manifiestan los prácticos que el camino que existe en esta depresión del terreno conduce a los saladeros de Elche [Camino del Colmenar], y está considerado también como otra vía pecuaria o Azagador, que atraviesa normalmente la que se está deslindando. Leída el acta fue aprobada [igual que las anteriores]».

«Acta del día 31. Se reanudaron los trabajos de deslinde en el barranco del Morriquet, la Comisión se encuentra bien orientada de la dirección y anchura que tiene la vía pecuaria por los hitos en este punto, pues así como desde el Collado del Portichol y entrando en el término de Alicante va por la ladera o vertiente $\mathrm{N}$. del monte de Colmenar sin que hayan fijado los peritos el rumbo de su eje, al llegar al citado barranco se observa que la vía pecuaria cruza este y sube al crestón de la Sierra y teniendo como límite a la izquierda o N. del corte vertical de las rocas que determinan la divisoria de las dos vertientes propiedad de D. Leandro Bas, y a la derecha o hacia el S. los mojones encontrados en el monte de los Sres. Bonmatí, se prosiguió el deslinde hasta llegar a una tierra llamada «La Capitana» propiedad de Rafael Dob [Dolç], en donde desaparecen los mojones que nos sirvieron de guía para el deslinde de este trozo de vía pecuaria, pero los prácticos manifestaron que continúan su trazado marchando por la loma de la Sierra hasta que se llegó al final de la misma donde existe una cantera que corta verticalmente el terreno y obliga a los ganados a hacer un pequeño rodeo hacia la derecha para bajar al Barranco de Aguas Amargas, por el que se siguió hasta su confluencia con el de la hacienda de Reyet y subiendo en dirección contraria a su corriente y por el 
alveo del mismo se llega al abrevadero de Aguas Amargas cuyas aguas vienen por acequia cubierta de trecho en trecho donde [desde] los manantiales de la hacienda de Burga propiedad de Doña Asunción Casanova límite y final de las operaciones de deslinde de la vía pecuaria, en cuyo punto manifestaron los peritos prácticos se bifurca dicha vía en dos ramales, uno que se dirige al pueblo de San Vicente del Raspeig, y otro a la falda del Castillo de San Fernando de Alicante, y próximo al cementerio de dicha capital. Leída la presente y estando en un todo conforme la firma de que yo el Secretario certifico. Siguen las firmas».

«Acta del 19 de abril. A indagaciones particulares por el Delegado Presidente de la Comisión pudo averiguar que en el trayecto comprendido desde el Portichol al barranco del Morriquet [o Camino del Colmenar], existen todavía mojones que determinan con precisión el verdadero trazado de la vía pecuaria por cuyo motivo reforzada la Comisión de deslinde con la asistencia de los hermanos Señores Bonmatí, el día 19 de abril se reanudaron los trabajos de deslinde practicado en minucioso y detenido reconocimiento de toda la ladera del monte de Colmenares, comprendido entre los dos puntos antes dichos; en entretenida operación porque de la disgregación de las rocas está saturado el suelo o terreno de cantos y piedras que dificultan la identificación de los verdaderos hitos, pero aún así se pudieron encontrar número suficiente para no dar lugar a duda por donde estaba trazada la vía pecuaria en esta zona de terreno que, al principio de las operaciones de deslinde el día 28 de marzo último, no se pudo aclarar con fijeza su verdadero rumbo. En este día pues, la Comisión se dedicó exclusivamente a rebuscar hitos por donde los señores Bonmatí manifestaban ha estado trazada la vía pecuaria, entre los puntos ya mencionados del Portichol al barranco del Morriquet. Leida el acta fue aprobada...».

«Acta del día 20 de abril. La comisión de deslinde acuerda en este día reconstruir digámoslo así, la traza de la vía pecuaria en toda la vertiente N. de la Sierra o monte Colmenares, a cuyo efecto partiendo del barranco Morriquet y dirigiéndose al Portichol, fue colocando nuevos hitos en los trayectos que se hallaron en el día anterior porque sin duda desaparecieron. Para llevar a feliz término esta operación se tomó la base del crestón la roca de la Sierra y en dirección de su pendiente, una anchura a distancia, e igual a la que aparece separados los mojones encontrados de dichas rocas, y en sitios visibles de uno a otro se fueron pintando los nuevos hitos empleando los mismos materiales y colocándolos en idéntica disposición de cómo fueron puestos los hoy existentes. Al propio tiempo se dio una lechada de cal a todos los mojones para que se destaquen de los cantos y piedras que en abundancia pueblan dicha ladera. En esta forma quedó señalada la dirección y anchura de la vía pecuaria en el trayecto que media entre el Portichol y barranco del Morriquet, diluciéndose las dudas que ofreció en un principio. Por consiguiente habiendo conformidad de pareceres en el resto del trazado, resulta perfectamente determinada la dirección de la vía pecuaria en todo su recorrido. Como se ve en el día de hoy la Comisión se ocupó exclusivamente de un 
previo amojonamiento para facilitar los trabajos topográficos. Leída que fue el acta se aprobó, de lo que yo el Secretario certifico».

«Acta del día 21 de abril. Como los trabajos de deslinde practicados en los días 28, 29 y 30 de marzo último, entre el monte y las tierras labrantinas [labrantías], queda anulado en lo concerniente a la dirección de la vía pecuaria, puesto que ya es conocido el verdadero rumbo de la misma; este es, que va por la parte alta de la ladera según se ha marcado en el día anterior, procedióse nuevamente a levantar el plano de la zona correspondiente entre el crestón de la sierra y las señales o hitos existentes con anterioridad y los colocados recientemente, comenzando la operación en la divisoria del término de Elche con el de Alicante y marchando por la línea de puntos o hitos señalados en el plano con los números 1, 2, 3, 4, etc. hasta llegar al 39 en su numeración correlativa, cuyo mojón se encuentra en el barranco de Morriquet y al lado derecho de la vía pecuaria que sabido es, cambia de dirección en este sitio pasando de la vertiente $\mathrm{N}$. a la del S.; es decir, que la línea de mojones del 1 al 38 en el límite izquierdo de la vía pastoril teniendo por margen a la derecha las rocas del monte y del mojón 39 en adelante, la línea de mojones va por la derecha o vertiente sur y a la izquierda de la vía pecuaria es el corte de las peñas. El trayecto recorrido todo fue por el monte de los señores de Bonmatí. Leida el acta fue aprobada....».

«Acta del día 22 de abril. Reunidos los trabajos de deslinde se continuaron las operaciones desde el mojón 39 que quedaron suspendidas el día anterior, que como hemos dicho está en el centro del barranco Morriquet, desde cuyo punto en adelante todos los hitos son antiguos menos uno, que se fijó en la finca de Rafaela Dolv [Dolçi], llamada «Capitani» al que corresponde el número 52 prosiguiendo por la loma de la sierra se fijaron dos señales sobre las rocas al final de la misma y tierra de Rafaela Dolv, punto C. y D. para marcar la desviación que tiene allí la vía pecuaria antes de bajar al barranco de Aguas Amargas por las excavaciones de la cantera de piedra que ya se ha hecho mención de ella, finalizando con esto las operaciones de deslinde, pues ya no ofrece duda la marcha que han de seguir los ganados por el centro del barranco de Aguas Amargas, hasta llegar al abrevadero del mismo nombre tal como se detalla en el plano que se acompaña. Leída el acta fue aprobada de lo que yo el Secretario certifico. Daniel García Llorca. Rafael Sempere. Juan Esteve. Manuel García. José Sempere. Juan Langucha. V. Ripoll.».

De acuerdo con el texto del acta de delimitación de la vía pecuaria entre el Portichol y el abrevadero del barranco de Aguas Amargas, en su mayor parte transcrito, la vía pecuaria deslindada tenía una longitud cercana a 5,5 km y una anchura aproximada de 22 metros, recibe los nombres de azagador, vereda, camino pastoril y vía pecuaria, indistintamente. De acuerdo con las indicaciones que en el acta de 1910 se hacen sobre los hitos de la vía pecuaria, ésta tuvo una delimitación o deslinde anterior, cuyos hitos en buena parte habían desaparecido en 1910. También resulta claro que el trazado de la vía pecuaria siempre fue junto a la línea de cumbres o divisoria de aguas de la Sierra de 
Colmenares, por su vertiente norte, de modo continuo entre el Portichol y barranco de Morriquet [Camino de Colmenares], y por la vertiente sur al este del citado barranco-camino.

El trazado de la vía pecuaria entre el Portichol y el abrevadero de Aguas Amargas, fue delineado en el Avance Catastral de 1923-1947 del término municipal de Alicante, según se comprueba en el croquis del polígono $\mathrm{n}^{\circ} 21$ (0134), entre el Portichol y el Camino de Colmenar, y en el polígono $\mathrm{n}^{\circ} 26$ (0139), entre el Camino del Colmenar y Barranco del Agua Amarga, donde la vía pecuaria es rotulada como «Vereda de Carne» (Fig. 3,A).

En el mapa parcelario de 1962-1991 (Fig.3, B), el trazado de esta antigua vía pecuaria ha desaparecido como tal, aunque es perfectamente identificable en la morfología parcelaria. La antigua vía pecuaria, siguiendo "costumbres» de siglos anteriores, ha sido absorbida por las parcelas limítrofes situadas a la izquierda de la vía pecuaria (dirección W-E), que sí se dibujan en el avance catastral de 1923-1947. Como se indica en las actas de deslinde de 1910, la vía ganadera se sitúa junto a la línea de cumbres de la Sierra de Colmenares, mientras que las amplias parcelas longitudinales que la «escoltan» en todo su recorrido entre el Portichol y el Barranco de Aguas Amargas -aunque con anchuras muy desiguales en estas parcelas-, parecen responder, o bien a terrenos con pendiente excesiva para usos agrarios, o bien a una zona de «seguridad» entre la vía de paso de los ganados, y las parcelas de cultivo. Estas últimas son de superficie muy reducida y con orientación longitudinal marcada por la pendiente de la Sierra, es decir perpendiculares a la vereda ganadera y a las grandes parcelas de «seguridad» entre vereda y cultivos.

En el texto del acta de deslinde de 1910 de la vía pecuaria entre el Portichol y el abrevadero de Aguas Amargas, se especifica que esta vía pecuaria es continuación de otra que procede de la Sierra Larga, en término de Elche, aunque parece que también es continuación de la Cañada-Vereda de Orihuela que llega al Portichol por el término de Elche, todo lo cual se traduce en su clasificación como «vía pecuaria de carácter general».

En efecto, en el Proyecto de clasificación de Vías Pecuarias del término municipal de Elche, fechado el 21-03-1991, realizado por los Servicios Territoriales de la Conselleria de Agricultura y Pesca, Unidad Forestal de Alicante (documentación facilitada en los Servicios Territoriales de Alicante de la Conselleria de Territori i Habitatge) se describen y cartografían a 1:25.000 un total de 23 vías pecuarias en el término de Elche (Fig. 4). Los trabajos de identificación de estas vías pecuarias fueron realizados por D. Felipe Gil Polo, Ingeniero Técnico Forestal. Según esta cartografía de las vías pecuarias de Elche y el texto de su clasificación, el extremo occidental de la vía pecuaria entre 

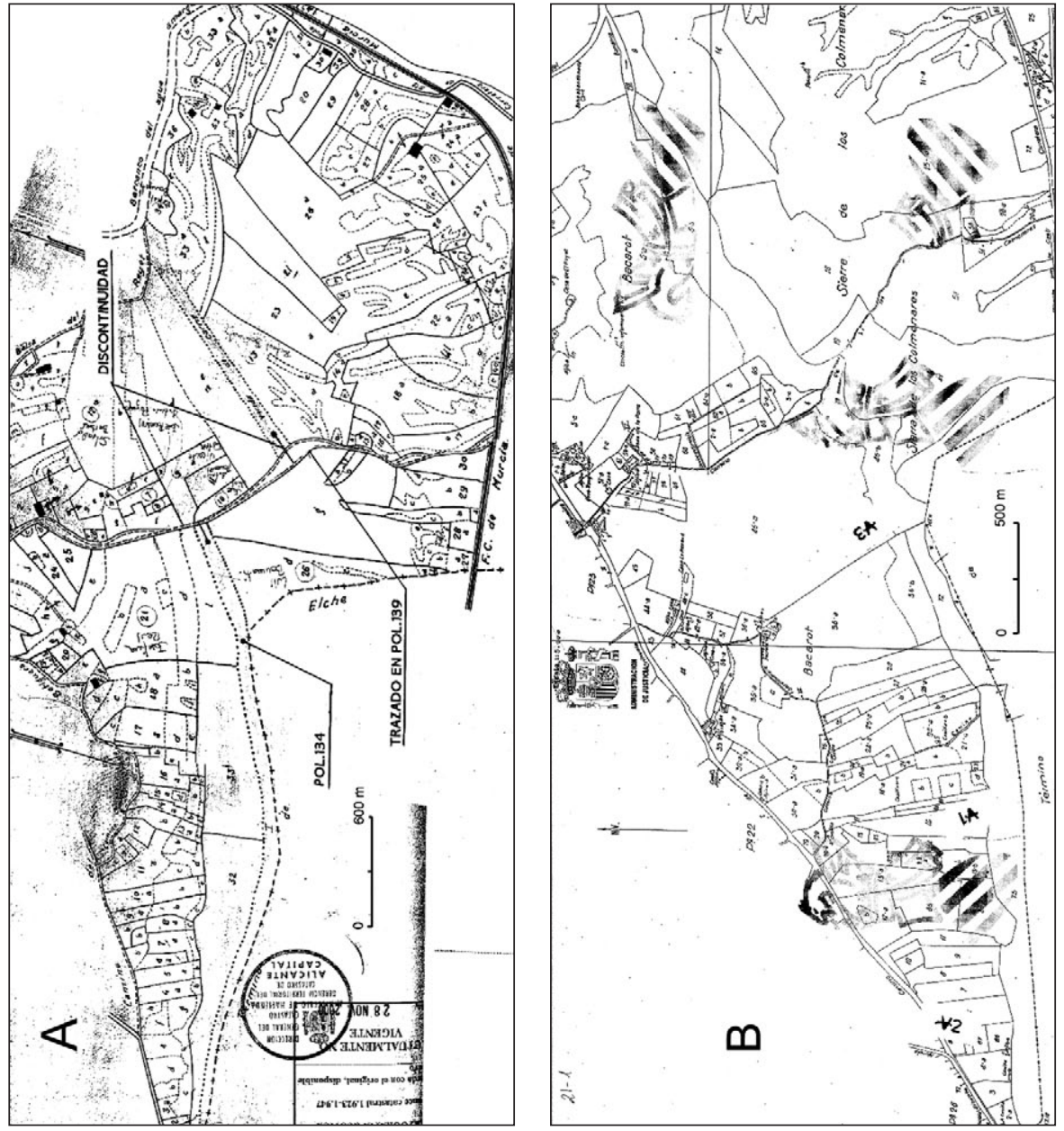

Fig. 3. Planos parcelarios de la ladera norte de la Sierra de Colmenares (Alicante) que incluyen la vereda pecuaria deslindada y amojonada en 1910 entre el Portichol y el Barranco de Agua Amarga. A, croquis del Avance Catastral de 1923-1947, en el que se dibuja todo el recorrido de la vereda rotulada como «vereda de carne». B, catastro vigente entre 1962 y 1991, donde el trazado de la vereda como tal ha desaparecido, pero sí es identificable en la forma que adopta el trazado parcelario. Las escalas gráficas de los planos son aproximadas.

el Portichol y el abrevadero de Aguas Amargas, coincide con la confluencia de las dos vías pecuarias principales que atraviesan el término de Elche de O. a E., que a su vez son cruzadas y/o dan origen o fin a otras varias vías pecuarias. Estas dos vías pecuarias principales que confluyen en el Portichol 
-donde se encuentra un extremo de la que nos ocupa en este estudio- son: la llamada en el informe de las vías pecuarias de Elche «Cañada de Orihuela a Alicante» (a la que se le asigna, no obstante, una anchura de sólo 20 metros), que continúa hacia la capital (Camino Viejo de Orihuela a Alicante), y la vía pecuaria número 16, denominada «Colada de Carayala o de los Mojones de Bru», que tiene su otro extremo en el cauce del río Vinalopó, junto al Molino de los Magros, aguas abajo del Pantano de Elche. A su vez, en este punto del río Vinalopó confluyen otras dos coladas, la número 17 (Colada del Puntal del Bubo [Buho] a las Peñas) que en su extremo opuesto enlaza con la colada del Camino Viejo de Crevillente, y la no 18 (Colada del Puntal del «Bubo» [Buho] al Tabayá), que procede del término de Monforte del Cid.

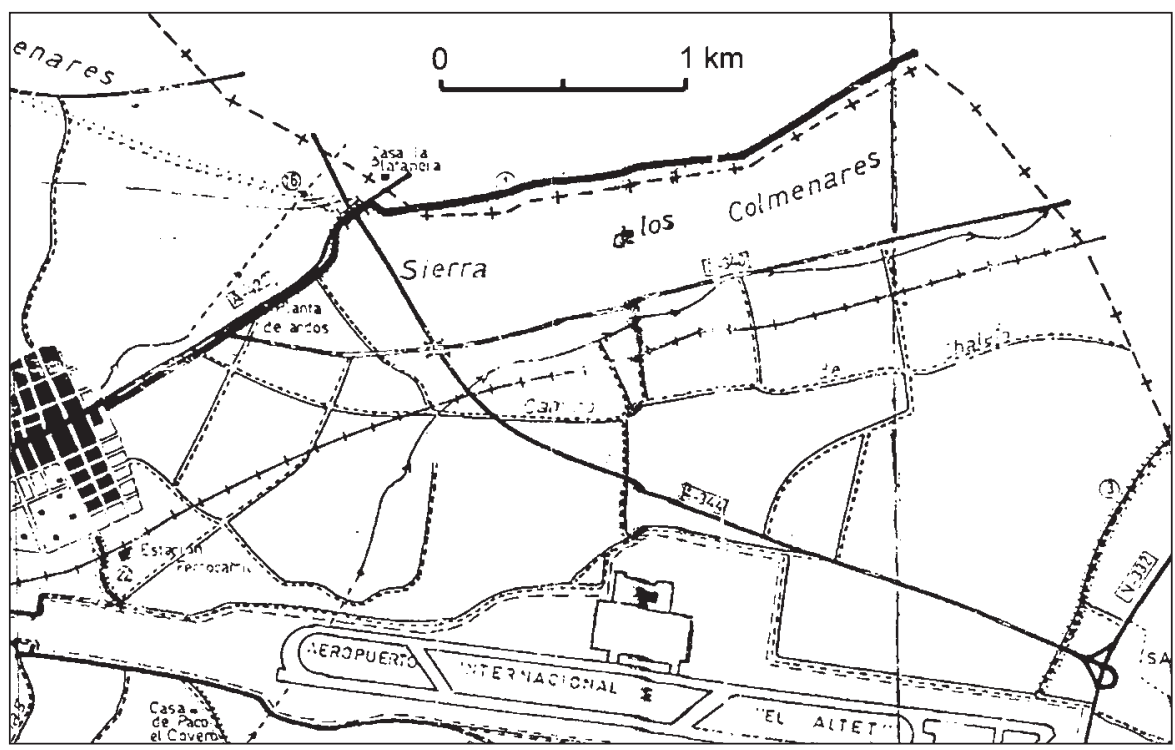

Fig. 4. Mapa de Vías Pecuarias del término municipal de Elche, año 1991. Zona de confluencia en el Portichol de la Cañada de Orihuela (1) y de la Colada de Caragola o de los Mojones de Bru (16).

Así pues, la confluencia de las dos vías pecuarias principales en el Portichol (Cañada de Orihuela a Alicante y Colada de Carayola o de los Mojones de Bru), y su continuidad por la parte superior de la ladera de la Sierra de Colmenares, hasta el abrevadero de Aguas Amargas, pueden ser base o explicación del amojonamiento de este tramo de vía pecuaria en 1910, pues sin duda esta vía pecuaria por la ladera superior de la Sierra de Colmenares debía 
canalizar un notable flujo ganadero procedente de la confluencia de vías pecuarias en el Portichol, que se dirigiría al abrevadero del barrando de Aguas Amargas, precisamente en un área de acusada aridez.

\subsection{La denominación «Cañada Real del Portichol»}

La documentación consultada sobre la vía pecuaria entre el Portichol y el abrevadero de Aguas Amargas, referida a distintas fechas de la primera mitad del siglo XX, en ningún caso ofrece la calificación de Cañada, sino la genérica de «vía pecuaria de carácter general», azagador y, en menor medida, vereda y camino pastoril. Según se especifica en oficio de la Asociación General de Ganaderos del Reino, fechado en Madrid el día 10 de octubre de 1908, ya trascrito anteriormente, en esa fecha al parecer la vía pecuaria -azagador- del Portichol no constaba en el Archivo de la Asociación. No obstante, según las actas del deslinde de dicha vía pecuaria realizado en marzo-abril de 1910, se especifica que con anterioridad dicha vía pecuaria ya había sido deslindada, al ser encontrados distintos hitos antiguos. Por otra parte, en el Avance catastral de 1923-1947 del municipio de Alicante, en los croquis de los polígonos 21 (0134) y 26 (0139) está cartografiada dicha vía pecuaria, que en el polígono 26 es rotulada como «Vereda de Carne», en clara alusión a su función ganadera. La confluencia de importantes vías pecuarias en el Portichol (como son la Cañada de Orihuela a Alicante y la Colada de Carayala o de los mojones de Bru -según consta en la clasificación de las vías pecuarias del término de Elche realizada en 1991-), y el inicio en este punto -en el Portichol- de una vía pecuaria que, por la ladera norte de la Sierra Colmenares, conducía al abrevadero de Aguas Amargas, sin duda fue decisivo para realizar el deslinde de dicha vía pecuaria - por su intensidad de paso ganadero y la necesidad del acceso al abrevadero-, con anchura media de 22 metros, según se especifica en el acta de deslinde de 1910.

Así, pues, de la documentación consultada no se pude deducir, a falta de nueva documentación, la existencia histórica de la «Cañada Real de Portichol», con anchura de 75,22 metros, que son el topónimo y la anchura que constan en el B.O.E., nº43, de 12 de febrero de 1955, en una orden del Ministerio de Agricultura de 31 de enero de 1955, firmada por el Director general de Ganadería, por la que se aprueba la clasificación de las vías pecuarias existentes en el término municipal de Alicante. Según consta en el texto de dicha Orden ministerial, la clasificación de estas vías pecuarias la realizó el Perito Agrícola D. Francisco Vázquez Gabaldón «al que habían servido de base los textos existentes en el archivo del Sindicato Nacional de Ganadería, una información testifical, plano del término del Instituto Geográfico y Catastral, 
habiendo sido oídas las opiniones del Ayuntamiento y de la Hermandad Sindical de Agricultores y Ganaderos y recorrido el término» ${ }^{26}$.

En el informe elaborado por D. Francisco Vázquez Gabaldón para la clasificación de las vías pecuarias del término municipal de Alicante, fechado el 30 de abril de 1954 (Fig. 5), se especifica que a la «Cañada Real del Portichol» «le corresponde según su denominación una anchura uniforme de noventa varas $(75,22$ metros)»; como detalle de la descripción de esta vía pecuaria, el autor del informe indica que la Cañada «entra en este término procedente del de Elche por el sitio denominado «El Portichol», por la Sierra de Colmenares, llevando como colindante por su izquierda a D. José Bonmatí y por su derecha la cumbre de la sierra y línea de Término de Alicante y Elche,.... «La Capitani» de la Sociedad Anónima «Aluminio Ibérico», continuando por la cantera hasta llegar al Barranco de Aguas Amargas y abrevadero de ganados donde finaliza. Encontrándose en la actualidad interceptada por recientes obras en construcción».

Es llamativo que los deslindes de vías pecuarias realizados en 1908 suelen aminorar la anchura legal de las vías pecuarias, al clasificar como veredas -unos 20 metros de anchura- las cañadas históricas - unos 75 metros de anchura-; por el contrario, en la propuesta de clasificación de la vía pecuaria

26. Según esta Orden ministerial, parece deducirse que el origen del encargo de redacción del expediente de clasificación de las vías pecuarias de Alicante, fue el esclarecimiento de un litigio de servidumbre ganadera entre la propietaria de la finca denominada «La Coronela», partida rural del Rebolledo, término de Alicante, y la Hermandad Sindical de Labradores y Ganaderos de Alicante. La propietaria de dicha finca, doña Manuela Díaz-Rubín, el 17-11-1952 denunció ante la Dirección General de Ganadería, que por su propiedad «se pretende pasar una servidumbre de ganados que jamás tuvo»; por su parte, la Hermandad de Labradores y Ganaderos el 17-01-1954 presentó otro escrito que «expone la denuncia presentada contra doña Manuela Díaz-Rubí, por haber destruido el abrevadero existente en la finca de su propiedad denominada «La Coronela», habiendo quedado inutilizado para su uso». Por su parte, según se especifica en el informe-proyecto (30-04-1954) de D. Francisco Vázquez Gabaldón, este litigo a que hace referencia la Orden ministerial de 31-01-1955, está localizado sobre «la Vereda del Desierto y Barranco del Infierno», que entra en término de Alicante desde el de Monforte. El litigio lo resuelve el informe con este texto: «Después [la Vereda] entra en la finca «La Corononela» de Doña Manuela Díaz de Rubín, llegando al Barranco del Infierno donde existe un abrevadero público por ser aguas que discurren del referido Barranco, pasándolas canalizadas por encima de la Vía Pecuaria cruzando el Barranco a la finca de la referida señora, prohibiendo en la actualidad abrevar a los ganados que desde tiempo inmemorial lo venían haciendo. Al salir del precitado Barranco por la referida propiedad de Doña Manuela Díaz, se encuentra la vía pecuaria amojonada con diez metros de anchura y blanqueados los mojones con cal hasta el límite de la mencionada finca donde ha cortado totalmente la vía pecuaria con una pared hecha de mampostería, teniendo que retroceder los ganados por estar plantada de pinos toda la superficie colindante con la vía pecuaria que corre a cargo del Distrito Forestal». 
entre el Portichol y el abrevadero de Aguas Amargas realizada en 1954, se aprueba el nombre de «Cañada Real del Portichol», con anchura de 75,22 metros, para una vía pecuaria que la documentación consultada de 1908, 1910 y 1912 califica indistintamente de azagador, vereda, camino pastoril o vía pecuaria, y se deslinda en 1910 con anchura media de 22 metros. En cualquier caso, también es preciso tener en cuenta el informe del Visitador de ganadería y cañadas de Orihuela enviado en 1908 a la Asociación de Ganaderos, ya

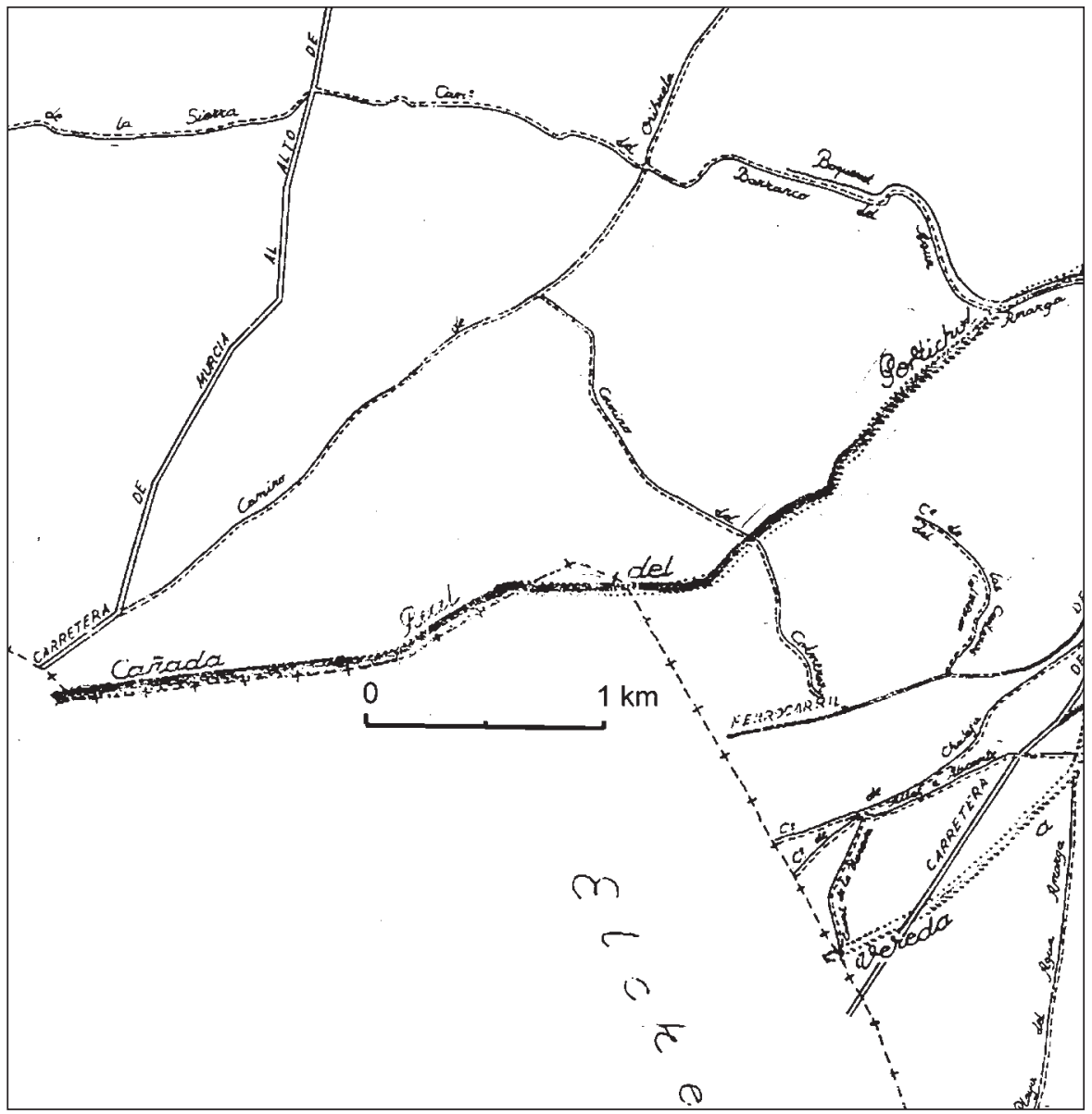

Fig. 5. Mapa de Vías Pecuarias en el término municipal de Alicante, año 1954. Trazado de la Cañada Real del Portichol, entre el Portichol y el Barranco de Agua Amarga, a la que se le asignó la anchura propia de su categoría viaria, 75,22 metros. Esta Cañada se corresponde con la vía pecuaria de carácter general delimitada y amojonada en 1910, sobre otra preexistente, a la que se le asignó anchura de unos 22 metros. 
reproducido en el epígrafe 3 de este estudio, que denuncia el estrechamiento de Cañada (90 varas) a vereda ( 25 varas) para la antigua Cañada procedente de Cuenca y Valencia a su paso por Orihuela.

En este sentido también resulta llamativa que en la clasificación de vías pecuarias del término municipal de Elche concluida en 1991 y publicada en DOGV como Orden de la Conselleria de Medi Ambient, de 22 de febrero de 1993, a la «Cañada de Oriola a Alacant» se asigna una anchura legal de 20 metros.

Finalmente hay que reseñar la documentación existente en el Archivo de la Cámara Agraria Provincial de Alicante, en una carpeta rotulada «Cañada del Portichol». Su documentación se inicia con una «copia mecanografiada del Proyecto de clasificación de las vías pecuarias del término municipal de Alicante firmado en abril de 1954 por el perito agrícola del Estado D. Francisco Vázquez. La mayor parte de la documentación que contiene la carpeta está fechada entre 1964 y 1967; suelen ser escritos de la Hermandad Sindical Local de Labradores y Ganaderos de Alicante, y hacen referencia a diversos conflictos por el uso de un camino vecinal que discurre por el tramo final del Barranco de Agua Amarga. En estos escritos con frecuencia se hace alusión a que por el cauce del barranco de Agua Amarga «discurre una Cañada Real de ganado, denominada "Cañada del Portichol», la cual tiene una anchura de setenta y cinco metros».

\subsection{Sintesis}

a) De acuerdo con la documentación consultada para este estudio, queda probada la existencia y uso ganadero de una vía pecuaria histórica que discurría por la ladera norte superior de la Sierra de Colmenares en el término municipal de Alicante, entre el punto denominado Portichol -como extremo oeste-, en la proximidad de la divisoria municipal entre Elche y Alicante, y un abrevadero situado en el barranco de Aguas Amargas en término de Alicante, donde terminaba. En el Portichol, donde se iniciaba esta vía pecuaria, confluían las dos vías pecuarias más importantes del término municipal de Elche, es decir la Cañada de Orihuela a Alicante y la Colada de Carayala o de los mojones de Bru: Estas dos vías recorrían de este a oeste el término municipal de Elche, la primera, a su vez, procedente de Orihuela, como indica su nombre, mientras el extremo oeste de la segunda vía enlazaba con otras dos coladas que se prolongaban, respectivamente, por los término de Crevillente y de Monforte del Cid.

La vía pecuaria entre el Portichol y el abrevadero de Aguas Amargas, consta en diversos documentos fechados en 1908, 1910, 1912 y en los planos 
del Avance Catastral del término municipal de Alicante de 1923-1947. En ninguno de estos documentos la citada vía pecuaria es calificada como «Cañada Real del Portichol», sino con los genéricos de vía pecuaria, azagador y, en menor medida vereda y camino pastoril. En 1908 en oficio remitido por la Asociación General de Ganaderos del Reino al Jefe de Fomento de la provincia de Alicante, se especifica que «En el Archivo de esta Corporación no aparecen datos del azagador que atraviesa de E. a O. y por la falda N. el monte denominado Colmenares...», aunque queda probada su existencia histórica en las actas del deslinde de esta vía pecuaria realizado en 1910, pues se hace frecuente referencia a hitos de deslinde de esta vía pecuaria anteriores a 1910.

Entre el 28 de marzo y el 22 de abril de 1910 se realizó un «deslinde de la vía pecuaria de Portichol al abrevadero de aguas amargas, en término de Alicante». Este deslinde fue realizado por una Comisión nombrada al efecto, ajustada a la legislación vigente, aunque sin representante de la Asociación General de Ganaderos del Reino. La actuación de la Comisión fue anunciada reglamentariamente en el Boletín Oficial de la provincia de Alicante, en la prensa local y también se puso en conocimiento de los propietarios de tierras colindantes a la vía pecuaria, a los que se invitó a estar presentes en los trabajos de campo de la Comisión. Tomaron parte en la preparación de la Comisión y en el anuncio de sus trabajos, al menos, el Jefe Provincial de Fomento de la provincia de Alicante, el Alcalde de Alicante y el Alcalde pedáneo de la partida rural de Bacarot. Según las actas de la Comisión, conservadas en el Archivo del Sindicato Nacional de Ganadería (Madrid), los trabajos de deslinde duraron ocho jornadas y la vía pecuaria deslindada tenía una anchura media de 22 metros y, según el plano, un recorrido de 5.433 metros.

En 1954 se realizó una clasificación de las vías pecuarias del término municipal de Alicante; el autor de esta clasificación fue D. Francisco Vázquez Gabaldón, Perito Agrícola del Estado, adscrito al Servicio de Vías Pecuarias de la Dirección General de Ganadería; esta clasificación fue publicada en el BOE de 12 de febrero de 1955, y en ella la vía pecuaria que nos ocupa fue calificada como «Cañada Real del Portichol» con anchura de 75,22 metros. Diversa documentación posterior a esta fecha -años 1964, 1966, 1967- emitida por la Hermandad Sindical Local de Labradores y Ganaderos de Alicante, siempre hace referencia a la citada clasificación de 1955, es decir Cañada Real de Portichol, con 75, 22 metros de ancho.

\section{CONCLUSIONES}

La Ley 3/1995, de 23 de marzo, de Vías Pecuarias (BOE de 24-03-1995) plantea el eslabón necesario entre la prístina función de las vías ganaderas y su 
devenir futuro, enmarcado en la prospectiva de las nuevas áreas rurales. Como se ha corroborado en los ejemplos de vías ganaderas citados en este estudio, la falta de uso de las vías pecuarias es factor fundamental de su degradación, e incluso de su desaparición. La Ley indica que es necesario salvaguardar el uso ganadero de las vías pecuarias, pero ante la insignificancia actual de éste, propone para las vías ganaderas otros usos compatibles y complementarios con las actividades pecuarias, acordes con la demanda social de las nuevas funciones de los espacios rurales.

Las comunidades Autónomas serán las responsables de preservar los vías pecuarias como bienes de dominio público, con carácter inalienable, imprescriptible e inembargable. Para ello tendrán el deber de investigar la situación de los terrenos que presuman pertenecientes a las vías pecuarias, pues, como se comprobó en los ejemplos citados, la pérdida de superficies por intrusión es muy frecuente y cuantiosa. Además de los usos ganaderos de las vías pecuarias, que siempre serán prioritarios, la nueva ley de 1995 propone que tales espacios (según cita de Cabo Alonso, 2004, en 39 de las provincias de España, el Resumen de la Labor del Servicio de Vias Pecuarias contabilizaba en 1969 un total de $152.626 \mathrm{~km}$ de longitud, para los que se calculaba una superficie superior a 500.000 hectáreas) puedan ser utilizados con usos compatibles con la ganadería, es decir a) para las comunicaciones rurales, sobre todo de vehículos y maquinaria agrícola, aunque también para vehículos que no sean de carácter agrícola, y b) para plantaciones lineales, cortavientos u ornamentales. Como usos complementarios de las vías pecuarias, la Ley especifica el paseo, la práctica del senderismo, la cabalgada y otras formas de desplazamiento deportivo sobre vehículos no motorizados.

Como se indica en la exposición de motivos de la Ley, las vías pecuarias, además de su uso ganadero, también deben ser consideradas como auténticos «corredores ecológicos», esenciales para la migración, la distribución geográfica y el intercambio genético de las especies silvestres. De acuerdo con la demanda social, la Ley señala que las vías pecuarias pueden constituir un instrumento favorecedor del contacto del hombre con la naturaleza y de la ordenación del entorno medioambiental. La evolución de la sociedad y de los espacios rurales, singularmente en los entornos de las áreas más urbanizadas, reafirman y acentúan las nuevas propuestas de uso para las vías pecuarias y sus interpretaciones ecológicas, que propuso la Ley hace quince años; aunque también es preciso insistir en la necesidad de una vigilancia creciente por parte de las Comunidades Autónomas para cumplir los objetivos y obligaciones que les asigna la Ley, incluidos la necesidad de potenciar estudios con esta finalidad; de ello da testimonio la creciente participación ciudadana en variadas 
asociaciones que vinculan la conservación y defensa de las vías pecuarias, con la protección medioambiental y la facilidad de acercamiento a la naturaleza para la sociedad urbanizada, lo que a su vez conlleva con frecuencia aumentar los recursos económicos de las áreas rurales por medio del turismo.

\section{BIBLIOGRAFÍA}

BONMATí ANTÓN, J.F (1989): La emigración alicantina a Argelia (Siglo XIX y primer tercio del siglo XX), Alicante, Universidad de Alicante y Caja de Ahorros Provincial de Alicante, $270 \mathrm{p}$.

CABO Alonso, A. (2004): «Funciones no ganaderas de las viejas vías pecuarias», en Rosselló Verger, V.M. y Gil Olcina, A. (Coords), Historia, clima y paisaje. Estudios geográficos en memoria del profesor Antonio López Gómez, Universitat de València, Universidad Autónoma de Madrid, Universitat d'Alacant, p. 99-110.

Cano García, G.M. (1974): La comarca de Baza, Valencia, Departamento de Geografía, Diputación Provincial de Granada, InstitutoJ.S. Elcano (C.S.I.C.), 523 p.

CAVANILLES, A.J. (1797): Observaciones sobre la historia natural, geografía, agricultura, población y frutos del Reino de Valencia, Madrid, Imprenta Real, 2 vols. Ed. Facsímil de Artes Gráficas Soler, Valencia, 1979.

GIMÉNEZ LóPEZ, E. (1981): Alicante en el siglo XVIII: Economía de una ciudad portuaria en el Antiguo Régimen, Valencia, Institución Alfonso el Magnánimo, $449 \mathrm{p}$.

GozÁlvez PÉReZ, V. (1972): «Notas sobre demografía de la provincia de Alicante», Cuadernos de Geografía, ${ }^{\circ} 11$, Universidad de Valencia, Facultad de Filosofía y Letras, p.27-77.

GoZÁlvez PéREZ, V. (1975): «Aspectos de Geografía política del Bajo Vinalopó», Revista del Instituto de Estudios Alicantinos, $\mathrm{n}^{\circ}$ 16, p. 33-49.

GozÁlVEZ PÉREZ, V. (1977): El Bajo Vinalopó. Geografía agraria, Valencia, Universidad de Valencia, Facultad de Filosofía y Letras, Departamento de Geografía, 270 p. + VIII láminas f.t.

GozÁlvez PÉREZ, V. (1983): Crevillente. Estudio urbano, demográfico e industrial, Alicante, Universidad de Alicante, Instituto Universitario de Geografía, 189 p.

GoZÁlVEZ PÉREZ, V. (1989): «Notas sobre el hábitat rural en la vega baja del río Segura (Alicante)», en GIL OlCinA, A. (coord.), Avenidas fluviales e inundaciones en la cuenca del Mediterráneo, Alicante, Instituto Universitario de Geografía de la Universidad de Alicante, Caja de Ahorros del Mediterráneo, p. 285-298. 